\title{
D\&M IS Success Model dan WebQual 4.0 pada Siakad Online STMIK Sinar Nusantara Surakarta
}

\author{
Yovita Kinanti Kumarahadi ${ }^{1)}$, Wing Wahyu Winarno ${ }^{2)}$, Mei Parwanto Kurniawan ${ }^{3)}$ \\ 1) Magister Teknik Informatika, Universitas Amikom Yogyakarta \\ 2) Akuntansi, STIE YKPN Yogyakarta \\ 3) Sistem Informasi, Universitas Amikom Yogyakarta \\ 1) yovita.k@students.amikom.ac.id, ${ }^{2)}$ wing@stieykpn.ac.id, ${ }^{3)}$ meikurniawan@amikom.ac.id
}

\begin{abstract}
Decision making must be accompanied by a strong foundation in which knows the net benefits felt by the system user. This study aims to determine the effect of variables on the D\&M IS Success Model and WebQual 4.0 in Siakad Online STMIK Sinar Nusantara Surakarta. This research used quantitative method with a questionnaire as a data collection tool. The results show that the research indicators and combination models get significant results. The indicator of research has a significant effect on the combination model. D\&M Model IS Success Model and WebQual 4.0 have significance value of $90 \%$ and $R^{2}$ of $84 \%$. It means information quality, system quality, service quality, and website qualityhave significance effects to Siakad Online intention to use and SiakadOnline's user satisfaction. Then, intention to use and user satisfaction have significance effects to SiakadOnline's user net benefits. Thus, this combination model is able to describe the relationship between indicators well. Suggestion that can be considered for future research is the addition of other external variables, such as gender.
\end{abstract}

Keywords: D\&M IS Success Model, siakad, net benefits, quality factor

\section{PENDAHULUAN}

Teknologi digital memiliki tujuan untuk memberikan kemudahan bagi pengguna dalam melakukan aktivitas (Ngafifi, 2014). Contoh penerapannya dalam bidang pendidikan adalah sistem informasi di institusi. Tujuan penerapan sistem informasi ini yaitu untuk memenuhi kebutuhan institusi dalam memberikan layanan pendidikan kepada pihak-pihak terkait, seperti mahasiswa, dosen, karyawan, hingga masyarakat (Al Fatta, 2007). Layanan pendidikan yang terkomputerisasi ini diharapkan mampu untuk meningkatkan kinerja, kualitas pelayanan, daya saing, serta kualitas sumber daya manusia yang dihasilkan (Aswati, Mulyani, Siagian, \& Syah, 2015). Dengan adanya sistem informasi, akses informasi menjadi semakin mudah untuk didapatkan, sehingga manfaatnya pun bisa dirasakan oleh pengguna sistem.

Penelitian ini fokus pada sistem informasi akademik (siakad) online di STMIK Sinar Nusantara Surakarta. Pengguna siakad meliputi mahasiswa, dosen, dan karyawan bidang akademik. Adanya perbedaan pengguna berarti terdapat perbedaan kebutuhan sehingga perlu dilakukan evaluasi terhadap sistem yang sedang berjalan (FKM-UNSRAT, n.d.). Dengan adanya evaluasi, dapat diketahui kelebihan serta kekurangan sistem sehingga dapat ditentukan bagian-bagian sistem yang perlu diperbaiki, ditingkatkan, maupun dipertahankan. Siakad Online menyediakan layanan kartu rencana studi, jadwal kuliah dan ujian, hingga konsultasi dengan dosen.

Terdapat tujuh indikator yang mempengaruhi kesuksesan suatu sistem, yaitu information quality, system quality, service quality, usage intentions, user satisfaction, dan system benefit. Variabel quality akan mempengaruhi usage intentions dan user satisfaction, kemudian pada akhirnya akan mempengaruhi net benefit. Hasilnya akan menunjukkan dampak dan manfaat yang diberikan sistem terhadap kebutuhan pengguna. Dengan mengetahui seberapa besar manfaat yang dirasakan oleh pengguna sistem, institusi dapat terbantu dalam pengambilan keputusan yang tepat. Sebelumnya belum pernah dilakukan 
evaluasi sistem pada Siakad Online STMIK Sinar Nusantara dengan melihat manfaat bersih oleh pengguna. Penelitian ini menggunakan metode DeLone McLean Model 2003 dan dikombinasikan dengan WebQual 4.0 untuk menilai kualitas website Siakad Online.

\section{TINJAUAN PUSTAKA}

Analisis tentang kesuksesan sistem sudah pernah dilakukan oleh beberapa peneliti. Alzahrani, Mahmud, Ramayah, \& Alfarraj (2017) melakukan penelitian pada sistem perpustakaan digital yang bertujuan untuk menentukan kegunaan nyata pada sistem tersebut. Hasil dari penelitian Alzahrani, Mahmud, Ramayah, \& Alfarraj (2017) adalah faktor kualitas dari sistem perpustakaan digital memiliki pengaruh yang kuat terhadap kepuasan, minat menggunakan, dan penggunaan nyata. Kualitas informasi adalah faktor terkuat untuk mengukur kepuasan pengguna. Kepuasan memiliki pengaruh kuat pada minat mahasiswa untuk menggunakan sistem. Kepuasan pengguna dan minat penggunaan sistem juga memiliki pengaruh positif yang signifikan dengan penggunaan nyata dari sistem perpustakaan digital. Dengan kata lain, minat menggunakan mendapat pengaruh besar dari kualitas sistem, kualitas informasi, dan kualitas pelayanan.

Rahayu, Aprilianto, \& Putro (2018) melakukan penelitian pada sistem informasi kemahasiswaan yang bertujuan untuk mengukur pengaruh system quality, information quality, dan service quality terhadap user satisfaction dan use serta mengetahui net benefit dari penggunaan sistem informasi terkait. Hasilnya adalah dari 10 hipotesis yang diuji, 5 dinyatakan diterima dan 5 dinyatakan ditolak. Saran yang diberikan oleh Rahayu, Aprilianto, \& Putro (2018) yaitu Diperlukan adanya peningktaan kualitas sistem, kualitas layanan, dan kualitas informasi agar memberikan pengaruh positif pada kepuasan pengguna, yang secara langsung akan memberikan pengaruh terhadap peningkatan minat penggunaan dan memberikan manfaat-manfaat bagi mahasiswa sebagai pengguna.

Yanti \& Nugroho (2018) melakukan penelitian tentang faktor penerimaan dan niat keberlanjutan penggunaan portal akademik siakad. Tujuan penelitian ini adalah mengevaluasi kesuksesan penerapan Siakad yang bertujuan untuk meningkatkan kualitas kinerja dan pelayanan dan sarana interaksi akademis antar dosen, mahasiswa serta bagian akademik berbasis teknologi informasi. Hasil penelitian Yanti \& Nugroho (2018) yaitu kepuasan pengguna dipengaruhi oleh kualitas informasi dan kualitas sistem. Sedangkan, niat keberlanjutan menggunkan dipengaruhi oleh kepuasan pengguna.

Absharina, Wijaya, \& Jaya (2018) melakukan penelitian kesukesesan sistem informasi E-KKN LP2M. Tujuan penelitian ini adalah untuk mengukur tingkat kesuksesan sistem informasi E-KKN berdasarkan pengaruh antar variabel pada model kesuksesan. Hasil yang didapatkan adalah kualitas sistem dan kualitas pelayanan berpengaruh terhadap pemakaian, sedangkan kualitas informasi tidak berpengaruh terhadap pemakaian.

Dalimunthe \& Pertiwi (2018) melakukan penelitian tentang kesuksesan penerapan SIKAD yang bertujuan untuk mengetahui tingkat kesuksesan penerapan SIKAD dan untuk mengetahui variabel yang mempengaruhi kepuasan pengguna. Hasil penelitian ini adalah Kualitas sistem berpengaruh terhadap kepuasan pengguna SIKAD, kualitas informasi dan kualitas layanan tidak berpengaruh terhadap kepuasan pengguna SIKAD.

Tarwoto \& Kuncoro (2019) melakukan penelitian tentang sistem informasi Smart Prodi untuk mengetahui tingkat kematangan sistem. Hasil penelitian ini adalah Kualitas sistem berpengaruh positif terhadap kepuasan pengguna dan manfaat bersih. Kualitas informasi dan kualitas layanan berpengaruh positif terhadap penggunaan, kepuasan pengguna, dan manfaat bersih. Penggunaan berpengaruh positif terhadap kepuasan pengguna dan manfaat bersih. Kepuasan pengguna berpengaruh positif terhadap penggunaan dan manfaat bersih. Manfaat bersih berpengaruh terhadap penggunaan dan kepuasan pengguna. 


\section{METODE PENELITIAN}

Metode penelitian merupakan prosedur dan teknik penelitian. Antara satu penelitian dan penelitian lain, prosedur dan tekniknya akan berbeda. Kalau tidak berbeda berarti penelitian itu hanya mengulang penelitian yang telah ada sebelumnya.

\subsection{JENIS, SIFAT, PENDEKATAN PENELITIAN}

Penelitian memerlukan data dalam mengungkap fakta yang diharapkan dapat sesuai dengan tujuan penelitian. Data yang digunakan dalam penelitian ini adalah data primer. Data primer merupakan data yang dikumpulkan langsung oleh peneliti dari sumber utamanya. Data primer yang dikumpulkan berupa angket yang disebarkan kepada mahasiswa STMIK Sinar Nusantara Surakarta.

Penelitian ini bertujuan untuk menguji hipotesis. Sekaran \& Bougie (2013) menyatakan bahwa pengujian hipotesis menjelaskan sifat dari hubungan tertentu atau membangun perbedaan dalam kelompok, maupun independensi dari dua atau lebih faktor pada sebuah situasi. Pengujian hipotesis digunakan untuk memberikan penjelasan mengenai perbedaan dalam variabel dependen. Penelitian ini menggunakan tipe investigasi penelitian kausal. Penelitian kausal adalah penelitian yang bertujuan untuk menggambarkan sebab dari satu masalah atau lebih.

Metode pengumpulan data yang dilakukan pada penelitian ini adalah observasi, angket, dan studi literatur. Observasi dilakukan secara langsung melalui Sistem Informasi Akademik Online STMIK Sinar Nusantara Surakarta. Angket yang disebarkan pada responden merupakan angket tertutup.

\subsection{POPULASI, SAMPEL, TEKNIK PENGAMBILAN SAMPEL}

Populasi penelitian ini adalah mahasiswa aktif semester ganjil di STMIK Sinar Nusantara Surakarta angkatan tahun 2013 hingga tahun 2019. Sampel penelitian didapatkan dengan menggunakan teknik Proportionate Stratified Random Sampling. Teknik ini digunakan karena populasi penelitian tidak homogen dan berstrata secara proporsional. Perhitungan jumlah sampel menggunakan rumus Slovin pada persamaan 1.

$$
n=\frac{N}{1+N(e)^{2}}
$$

dimana $\mathrm{n}=$ ukuran sampel, $\mathrm{N}=$ jumlah populasi, dan $\mathrm{e}=$ alpha. Perhitungan jumlah sampel berstrata dilakukan dengan menggunakan rumus alokasi proportional pada persamaan 2.

$$
n i=\frac{N i}{N} \times n
$$

dimana ni = jumlah sampel menurut stratum, $\mathrm{n}=$ jumlah sampel seluruhya, $\mathrm{Ni}=$ jumlah populasi menurut stratum, dan $\mathrm{N}=$ jumlah populasi seluruhnya.

\subsection{VARIABEL PENELITIAN}

Variabel yang digunakan pada penelitian ini yaitu kualitas informasi (information quality) sebagai variabel bebas pertama (X1), kualitas sistem (system quality) sebagai variabel bebas kedua (X2), kualitas layanan (service quality) sebagai variabel bebas ketiga (X3), kualitas web (web quality) sebagai variabel bebas keempat (X4), minat penggunaan (intention to use) sebagai variabel intervening pertama (Z1), kepuasan pengguna (user satisfaction) sebagai variabel intervening kedua (Z2), dan manfaat bersih (net benefits) sebagai variabel dependen (Y).

\subsection{MODEL PENELITIAN}

Model yang digunakan pada penelitian adalah DeLone and McLean Model dan WebQual 4.0. 


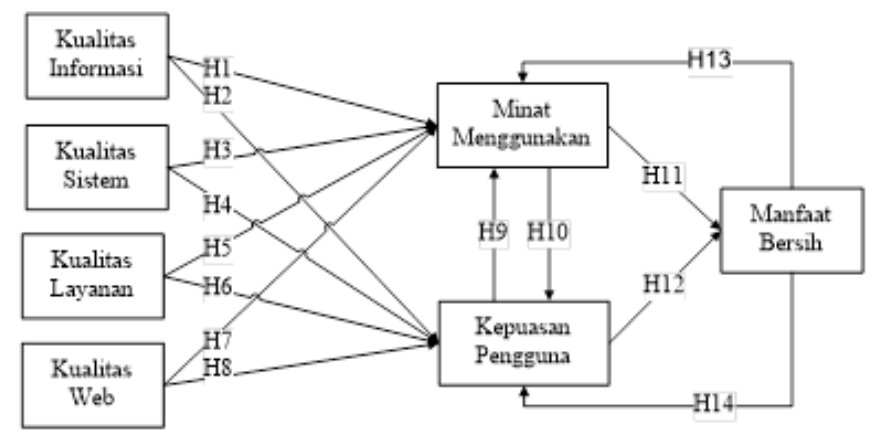

Gambar 1. Model Penelitian

Gambar 1 menunjukkan kombinasi DeLone and McLean IS Success Model dengan WebQual 4.0. Kualitas informasi, kualitas sistem, dan kualitas layanan merupakan bagian dari DeLone and McLean IS Success Model, sedangkan kualitas web merupakan bagian dari WebQual 4.0.

\subsection{METODE ANALISIS DATA}

Dalam melakukan analisis data, terdapat beberapa tahapan yang dilakukan: uji alat pengambil data yang terdiri dari uji reliabilitas; uji teknik analisis data yang terdiri dari goodness of fit dan analisa pengaruh dan jalur. Pada uji alat pengambil data, dilakukan uji reliabilitas dengan menggunakan rumus Crobach Alpha pada persamaan 3, dimana $\mathrm{r}_{11}=$ reliabilitas instrument, $\mathrm{k}=$ banyak butir pertanyaan, $\Sigma=$ jumlah total, $\sigma_{b^{2}}=$ varians butir, $\sigma_{t^{2}}=$ varians total.

$$
r_{11}=\left(\frac{k}{k-1}\right)\left(1-\frac{\left(\sum \sigma_{b^{2}}\right)}{\sigma_{t^{2}}}\right) \ldots \ldots \ldots
$$

\subsection{PROSEDUR PENELITIAN} Gambar 2.

Berdasarkan uraian sebelumnya, dapat ditentukan prosedur penelitian seperti pada

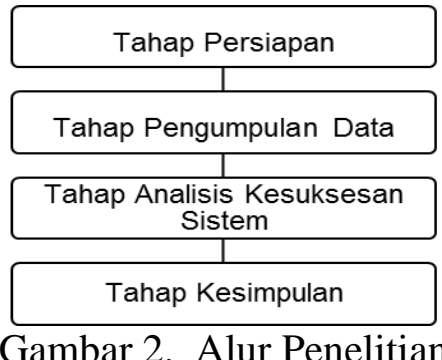

Alur penelitian terdiri dari tahap persiapan, tahap pengumpulan data, tahap analisis kesuksesan sistem, dan tahap kesimpulan. Pada tahap persiapan, proses yang dilakukan adalah perumusan masalah, penentuan judul, penetapan tujuan, dan studi literatur. Pada tahap pengumpulan data, proses yang dilakukan adalah penentuan metode dan variabel, perumusan hipotesis, penyusunan kuisioner, dan penyebaran kuisioner. Pada tahap analisis kesuksesan sistem, proses yang dilakukan adalah pengujian alat pengambil data dan analisis data. Pada tahap kesimpulan, proses yang dilakukan adalah penarikan kesimpulan sesuai hasil analisa data.

\section{HASIL DAN PEMBAHASAN}

\subsection{Hasil Pemilihan Sampel}

Sampel penelitian didapatkan dengan menggunakan persamaan 1 dengan alpha 5\%, kemudian ditentukan besaran sampel per stratum dengan menggunakan persamaan 2 . 
Stratum yang digunakan dilihat dari program studi mahasiswa STMIK Sinar Nusantara Surakarta, yaitu diploma manajemen informatika (MI D3), diploma komputerisasi akuntansi (KA D3), diploma teknologi informasi (TI D3), strata sistem informasi (SI S1), dan strata teknologi informasi (TI S1). Sampel merupakan jumlah minimal responden dalam penelitian yang ditentukan supaya masing-masing jenis responden dapat terwakili. Jumlah sampel dapat dilihat dari Tabel 1.

Tabel 1 Populasi dan Sampel

\begin{tabular}{|c|r|r|r|}
\hline Jurusan & Populasi & Sampel & \multicolumn{1}{|c|}{$\%$} \\
\hline MI -D3 & 38 & 11 & 4 \\
\hline KA - D3 & 10 & 3 & 1 \\
\hline TI - D3 & 83 & 23 & 8 \\
\hline SI - S1 & 329 & 92 & 32 \\
\hline TI - S1 & 566 & 159 & 55 \\
\hline Jumlah & 1026 & 288 & 100 \\
\hline
\end{tabular}

Pengumpulan data dilakukan dengan penyebaran kuisioner yang dirancang sesuai dengan indikator dari IS Success Model dan WebQual. Indikator dari IS Success Model berjumlah 23 butir dan indikator dari WebQual berjumlah 13 butir, sehingga total indikator yang digunakan untuk penelitian adalah sejumlah 36 butir. Indikator kuisioner dapat dilihat pada Tabel 2.

Tabel 2. Indikator Kuisioner

\begin{tabular}{|c|c|c|}
\hline Variabel & Indikator & Model \\
\hline \multirow{4}{*}{$\begin{array}{l}\text { Kualitas } \\
\text { Sistem }\end{array}$} & $\begin{array}{l}\text { mudah dipahami dan } \\
\text { dioperasikan }\end{array}$ & \multirow{4}{*}{ IS } \\
\hline & $\begin{array}{l}\text { melayani kebutuhan } \\
\text { info }\end{array}$ & \\
\hline & info waktu singkat & \\
\hline & akses mudah & \\
\hline \multirow{6}{*}{$\begin{array}{l}\text { Kualitas } \\
\text { Informasi }\end{array}$} & info lengkap & \multirow{6}{*}{ IS } \\
\hline & info tak ambigu & \\
\hline & info tepat waktu & \\
\hline & $\begin{array}{l}\text { info mudah } \\
\text { dimengerti }\end{array}$ & \\
\hline & detail tepat & \\
\hline & format sesuai & \\
\hline \multirow{4}{*}{$\begin{array}{l}\text { Kualitas } \\
\text { Layanan }\end{array}$} & $\begin{array}{l}\text { info dapat } \\
\text { dipertanggung } \\
\text { jawabkan }\end{array}$ & \multirow{4}{*}{ IS } \\
\hline & $\begin{array}{l}\text { pengelola dapat } \\
\text { dihubungi }\end{array}$ & \\
\hline & $\begin{array}{l}\text { info bermanfaat dan } \\
\text { memadai }\end{array}$ & \\
\hline & info cepat dan tepat & \\
\hline \multirow{5}{*}{ Kegunaan } & mudah dipelajari & \multirow{5}{*}{ WQ } \\
\hline & $\begin{array}{l}\text { interaksi mudah } \\
\text { dipahami }\end{array}$ & \\
\hline & navigasi mudah & \\
\hline & mudah digunakan & \\
\hline & tampilan menarik & \\
\hline
\end{tabular}

\begin{tabular}{|c|c|c|}
\hline Variabel & Indikator & Model \\
\hline \multirow{3}{*}{ Kegunaan } & desain sesuai & \multirow{3}{*}{ WQ } \\
\hline & $\begin{array}{l}\text { mengandung } \\
\text { kompetensi }\end{array}$ & \\
\hline & pengalaman positif & \\
\hline \multirow{5}{*}{$\begin{array}{l}\text { Desain } \\
\text { Interaksi }\end{array}$} & reputasi baik & \multirow{5}{*}{ WQ } \\
\hline & aman & \\
\hline & $\begin{array}{l}\text { ruang untuk } \\
\text { personalisasi }\end{array}$ & \\
\hline & $\begin{array}{l}\text { ruang untuk } \\
\text { komunitas }\end{array}$ & \\
\hline & $\begin{array}{l}\text { proses berjalan } \\
\text { optimal }\end{array}$ & \\
\hline \multirow{3}{*}{$\begin{array}{l}\text { Mina } \\
\text { tMenggunakan }\end{array}$} & minat & \multirow{3}{*}{ IS } \\
\hline & akses sering & \\
\hline & $\begin{array}{l}\text { akses untuk dapat info } \\
\text { akademis }\end{array}$ & \\
\hline \multirow{3}{*}{$\begin{array}{l}\text { Kepuasan } \\
\text { Pengguna }\end{array}$} & $\begin{array}{l}\text { membantu mencari } \\
\text { info cepat }\end{array}$ & \multirow{3}{*}{ IS } \\
\hline & $\begin{array}{l}\text { info sesuai yang } \\
\text { diharapkan }\end{array}$ & \\
\hline & puas dengan layanan & \\
\hline \multirow{3}{*}{$\begin{array}{l}\text { Manfaat } \\
\text { Bersih }\end{array}$} & $\begin{array}{l}\text { meningkatkan } \\
\text { pengetahuan }\end{array}$ & \multirow{3}{*}{ IS } \\
\hline & $\begin{array}{l}\text { info dapat dibagi } \\
\text { dengan mudah }\end{array}$ & \\
\hline & $\begin{array}{l}\text { waktu mencari info } \\
\text { singkat }\end{array}$ & \\
\hline
\end{tabular}

Kuisioner yang diterima kembali akan diperiksa terlebih dahulu untuk memilih kuisioner yang dapat diolah dan tidak dapat diolah. Tabel 3 menunjukkan jumlah kuisioner 
tiap jurusan. Dari 481 kuisioner yang disebar, terdapat 82 kuisioner yang tidak dapat diolah, sehingga kuisioner yang dapat diolah berjumlah 399.

Tabel 3 Pengumpulan Data

\begin{tabular}{|l|r|r|r|r|r|}
\hline Keterangan & MI - D3 & KA - D3 & TI - D3 & SI - S1 & TI - S1 \\
\hline Kuisioner disebar & 38 & 10 & 83 & 150 & 200 \\
\hline Kuisioner tidak kembali & 3 & 1 & 8 & 17 & 24 \\
\hline Isi kuisioner sama semua & 0 & 0 & 0 & 9 & 11 \\
\hline Pengisian data tidak lengkap & 1 & 0 & 2 & 2 & 4 \\
\hline Kuisioner yang dapat diolah & 34 & 9 & 73 & 122 & 161 \\
\hline \multicolumn{6}{|r|}{ Total Kuisioner yang dapat diolah } \\
\hline
\end{tabular}

\subsection{Pengujian Alat Pengambil Data}

Uji alat pengambil data dilakukan dengan uji reliabilitas. Uji reliabilitas menunjukkan tingkat keyakinan pada variabel yang diolah. Berdasarkan perhitungan dengan menggunakan persamaan 3, didapatkan hasil perhitungan sebesar 0,982. Dengan demikian dapat disimpulkan bahwa kuisioner sudah reliabel dan dapat digunakan untuk mengambil data.

\subsection{Pengujian Analisis Data}

Analisis data dilakukan dalam beberapa tahap seperti pada Gambar 3. Goodness of fit memiliki tujuan untuk mengetahui kesesuaian model, validitas variabel, dan signifikansi pengaruh. Analisa pengaruh dan jalur memiliki tujuan untuk mengetahui besar pengaruh antar variabel.

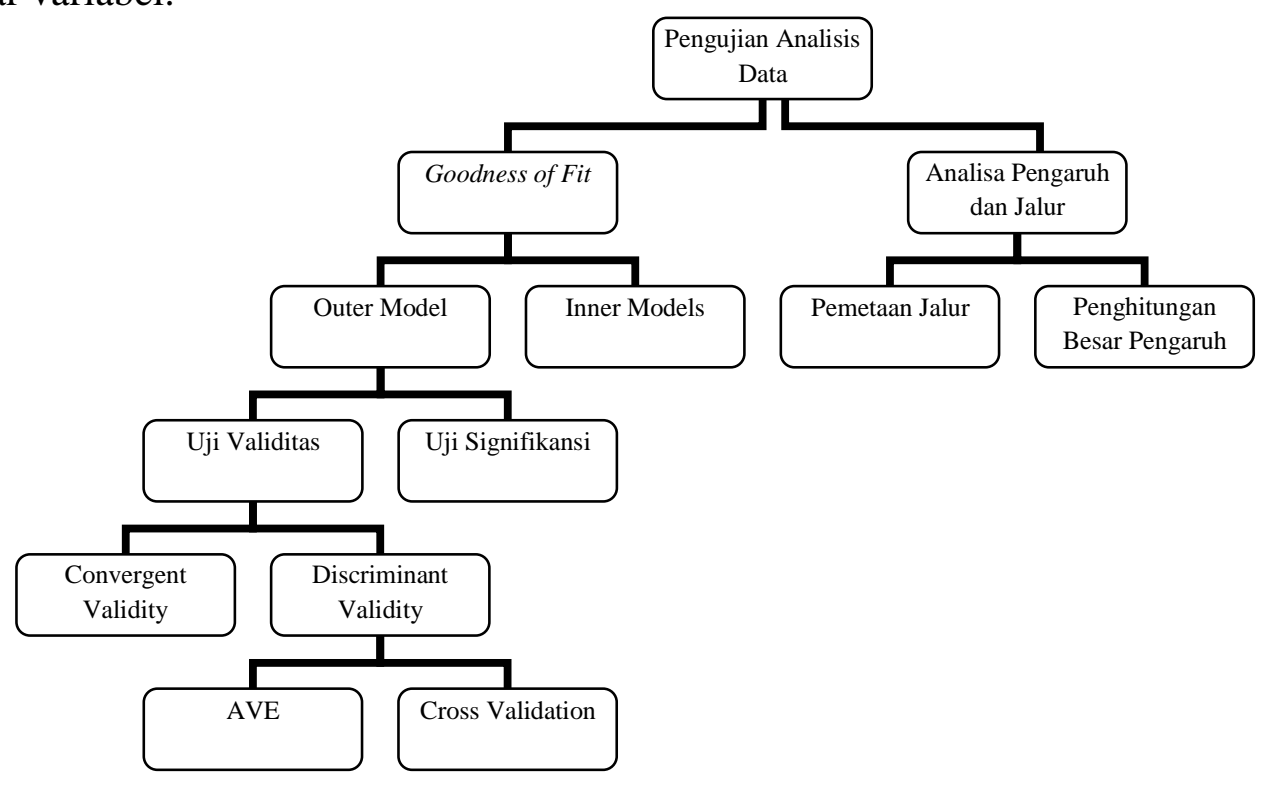

Gambar 3. Alur Pengujian Analisis Data

Pada Gambar 3, Goodness of fit terdiri dari pengujian dua model, yaitu outer models (measurement model) dan inner models (structural model). Dalam menganalisis outer model, perlu dilakukan dua jenis uji yaitu validitas dan signifikansi. Uji validitas terdiri dari convergent validity dan discriminant validity. Sedangkan uji signifikansi terdiri dari bootstrapping. 


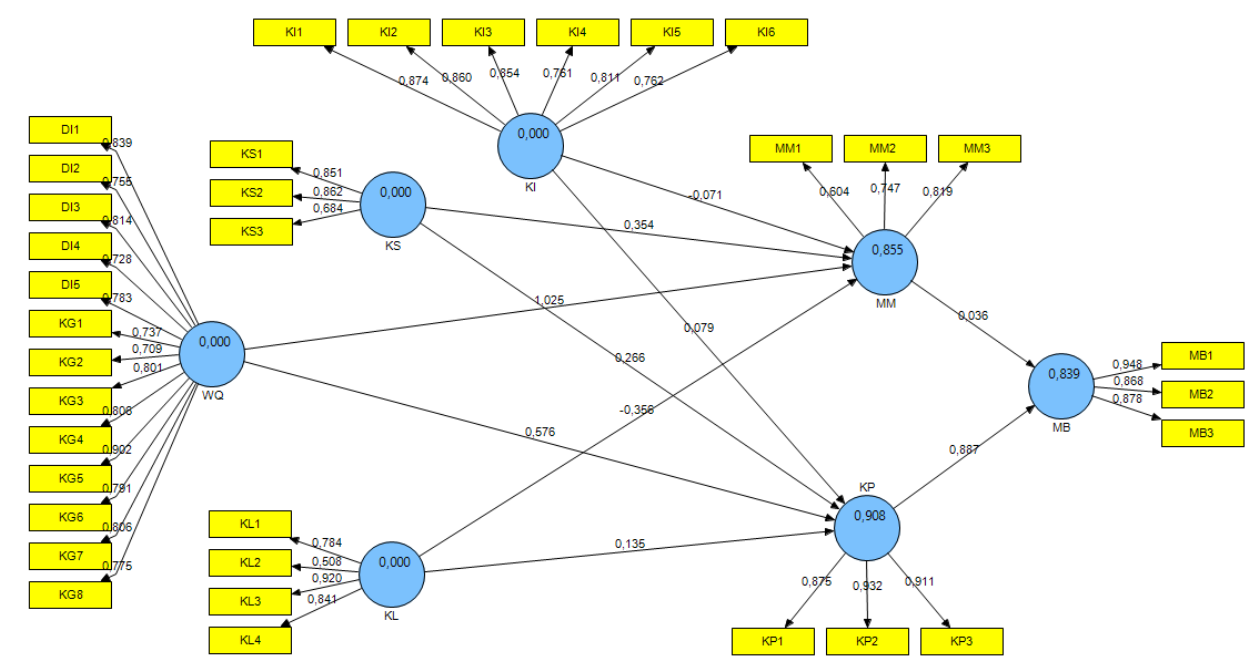

Gambar 4. PLS Algorithm Output (Sumber: Olah Data Penelitian)

Berdasarkan gambar 4, apabila $\lambda$ (loading factor) lebih besar atau sama dengan 0,5 maka indikator valid secara konvergen. Sebaliknya, apabila nilai loading factor lebih kecil dari 0,5 maka indikator tidak valid secara konvergen.

Tabel 3 Nilai Loading Factor

\begin{tabular}{|c|c|c|}
\hline \multicolumn{2}{|c|}{ Nilai Loading Factor } & Hasil \\
\hline$\lambda \mathrm{DI} 1$ & 0,8393 & Valid \\
\hline$\lambda \mathrm{DI} 2$ & 0,7551 & Valid \\
\hline$\lambda \mathrm{DI} 3$ & 0,8144 & Valid \\
\hline$\lambda \mathrm{DI} 4$ & 0,7282 & Valid \\
\hline$\lambda \mathrm{DI} 5$ & 0,7828 & Valid \\
\hline$\lambda \mathrm{KG} 1$ & 0,7373 & Valid \\
\hline$\lambda \mathrm{KG} 2$ & 0,7088 & Valid \\
\hline$\lambda \mathrm{KG} 3$ & 0,8007 & Valid \\
\hline$\lambda \mathrm{KG} 4$ & 0,8056 & Valid \\
\hline$\lambda \mathrm{KG} 5$ & 0,9021 & Valid \\
\hline$\lambda \mathrm{KG} 6$ & 0,7910 & Valid \\
\hline$\lambda \mathrm{KG} 7$ & 0,8063 & Valid \\
\hline$\lambda \mathrm{KG} 8$ & 0,7748 & Valid \\
\hline$\lambda \mathrm{KI} 1$ & 0,8742 & Valid \\
\hline$\lambda \mathrm{KI} 2$ & 0,8597 & Valid \\
\hline$\lambda \mathrm{KI} 3$ & 0,8544 & Valid \\
\hline$\lambda \mathrm{KI} 4$ & 0,7607 & Valid \\
\hline$\lambda \mathrm{KI} 5$ & 0,8109 & Valid \\
\hline
\end{tabular}

\begin{tabular}{|c|c|c|}
\hline \multicolumn{2}{|c|}{ Nilai Loading Factor } & Hasil \\
\hline$\lambda \mathrm{KI} 6$ & 0,7617 & Valid \\
\hline$\lambda \mathrm{KL} 1$ & 0,7842 & Valid \\
\hline$\lambda \mathrm{KL} 2$ & 0,5082 & Valid \\
\hline$\lambda \mathrm{KL} 3$ & 0,9198 & Valid \\
\hline$\lambda \mathrm{KL} 4$ & 0,8408 & Valid \\
\hline$\lambda \mathrm{KP} 1$ & 0,8752 & Valid \\
\hline$\lambda \mathrm{KP} 2$ & 0,9315 & Valid \\
\hline$\lambda \mathrm{KP} 3$ & 0,9113 & Valid \\
\hline$\lambda \mathrm{KS} 1$ & 0,8514 & Valid \\
\hline$\lambda \mathrm{KS} 2$ & 0,8622 & Valid \\
\hline$\lambda \mathrm{KS} 3$ & 0,6841 & Valid \\
\hline$\lambda \mathrm{MB} 1$ & 0,9483 & Valid \\
\hline$\lambda \mathrm{MB} 2$ & 0,8681 & Valid \\
\hline$\lambda \mathrm{MB} 3$ & 0,8777 & Valid \\
\hline$\lambda \mathrm{MM} 1$ & 0,6043 & Valid \\
\hline$\lambda \mathrm{MM} 2$ & 0,7471 & Valid \\
\hline$\lambda \mathrm{MM} 3$ & 0,8188 & Valid \\
\hline
\end{tabular}

(Sumber: Olah Data Penelitian)

Tabel 3 menunjukkan bahwa semua indikator memiliki nilai loading factor lebih besar dari 0,5 sehingga dapat disimpulkan bahwa indikator pada model valid secara konvergen. Analisa selanjutnya adalah discriminant validity, yang dilakukan dengan dua acara yaitu melihat nilai AVE dan cross validation. Variabel dinyatakan secara discriminant apabaila AVE menunjukkan nilai lebih besar dari 0,5. 
Tabel 4. Nilai AVE

\begin{tabular}{|l|l|l|}
\hline Variabel & AVE & Hasil \\
\hline KI & 0,675 & Valid \\
\hline KL & 0,6066 & Valid \\
\hline KP & 0,8214 & Valid \\
\hline KS & 0,6455 & Valid \\
\hline MB & 0,8077 & Valid \\
\hline MM & 0,5312 & Valid \\
\hline WQ & 0,6236 & Valid \\
\hline
\end{tabular}

(Sumber: Olah Data Penelitian)

Berdasarkan Tabel 4, seluruh variabel menunjukkan nilai AVE diatas 0,5. Dengan demikian, variabel penelitian valid secara discriminant. Untuk nilai cross loadings, indikator dinyatakan valid apabila nilai loadings indikator terhadap variabel terkait lebih besar dibandingkan nilai loadings indikator terhadap variabel lain.

Tabel 5. Cross Loading

\begin{tabular}{|c|c|c|c|c|c|c|c|}
\hline & KI & KL & KP & KS & MB & MM & WQ \\
\hline DI1 & 0,7881 & 0,7680 & 0,8393 & 0,6800 & 0,7546 & 0,7855 & 0,9046 \\
\hline DI2 & 0,5114 & 0,6293 & 0,6494 & 0,4365 & 0,6270 & 0,6520 & 0,7551 \\
\hline DI3 & 0,5704 & 0,5059 & 0,6826 & 0,3556 & 0,7067 & 0,6932 & 0,8144 \\
\hline DI4 & 0,4729 & 0,4190 & 0,5670 & 0,1977 & 0,5488 & 0,6067 & 0,7282 \\
\hline DI5 & 0,5224 & 0,5864 & 0,7078 & 0,3364 & 0,7425 & 0,6204 & 0,7828 \\
\hline KG1 & 0,7373 & 0,7875 & 0,7416 & 0,7852 & 0,7455 & 0,6860 & 0,8041 \\
\hline KG2 & 0,6700 & 0,5804 & 0,6383 & 0,4655 & 0,5937 & 0,6776 & 0,7088 \\
\hline KG3 & 0,4914 & 0,4660 & 0,6168 & 0,2481 & 0,6021 & 0,7003 & 0,8007 \\
\hline KG4 & 0,5553 & 0,5396 & 0,7117 & 0,3896 & 0,7400 & 0,6685 & 0,8056 \\
\hline KG5 & 0,6929 & 0,5983 & 0,7929 & 0,4303 & 0,8354 & 0,7947 & 0,9021 \\
\hline KG6 & 0,7910 & 0,7201 & 0,7416 & 0,5320 & 0,7117 & 0,7558 & 0,8271 \\
\hline KG7 & 0,8063 & 0,7737 & 0,8188 & 0,5938 & 0,7153 & 0,7884 & 0,8466 \\
\hline KG8 & 0,5380 & 0,5588 & 0,5944 & 0,4541 & 0,6224 & 0,7277 & 0,7748 \\
\hline KI1 & 0,8742 & 0,7007 & 0,7050 & 0,5923 & 0,6507 & 0,6211 & 0,6793 \\
\hline KI2 & 0,8597 & 0,7699 & 0,6864 & 0,6374 & 0,6813 & 0,5107 & 0,6636 \\
\hline KI3 & 0,8544 & 0,7671 & 0,7331 & 0,4745 & 0,7474 & 0,6577 & 0,7626 \\
\hline KI4 & 0,7607 & 0,5541 & 0,6996 & 0,6237 & 0,6890 & 0,6679 & 0,7294 \\
\hline KI5 & 0,8109 & 0,7514 & 0,7046 & 0,6819 & 0,6754 & 0,5470 & 0,6217 \\
\hline KI6 & 0,7617 & 0,6979 & 0,7296 & 0,6921 & 0,6828 & 0,5623 & 0,5632 \\
\hline KL1 & 0,6922 & 0,7842 & 0,6835 & 0,6471 & 0,6265 & 0,5290 & 0,6116 \\
\hline KL2 & 0,3770 & 0,5626 & 0,4544 & 0,2794 & 0,4446 & 0,4513 & 0,5082 \\
\hline KL3 & 0,7379 & 0,9198 & 0,7953 & 0,7053 & 0,7338 & 0,5519 & 0,6882 \\
\hline KL4 & 0,8093 & 0,8408 & 0,6943 & 0,7064 & 0,6266 & 0,5173 & 0,5723 \\
\hline KP1 & 0,7361 & 0,7108 & 0,8752 & 0,6541 & 0,8179 & 0,7217 & 0,7555 \\
\hline KP2 & 0,8546 & 0,8410 & 0,9315 & 0,8346 & 0,8501 & 0,7263 & 0,8133 \\
\hline KP3 & 0,7605 & 0,7803 & 0,9113 & 0,5933 & 0,8217 & 0,7411 & 0,8825 \\
\hline KS1 & 0,6627 & 0,6803 & 0,7089 & 0,8514 & 0,6019 & 0,5289 & 0,5622 \\
\hline KS2 & 0,6447 & 0,7170 & 0,6794 & 0,8622 & 0,6625 & 0,5792 & 0,5024 \\
\hline KS3 & 0,4769 & 0,4211 & 0,4103 & 0,6841 & 0,3820 & 0,3740 & 0,3089 \\
\hline MB1 & 0,7834 & 0,7851 & 0,8821 & 0,7010 & 0,9483 & 0,6760 & 0,8219 \\
\hline MB2 & 0,8050 & 0,6849 & 0,7926 & 0,4476 & 0,8681 & 0,7356 & 0,8419 \\
\hline MB3 & 0,6746 & 0,6625 & 0,7906 & 0,7404 & 0,8777 & 0,6111 & 0,6990 \\
\hline MM1 & 0,4706 & 0,3733 & 0,5445 & 0,2164 & 0,5040 & 0,6664 & 0,6043 \\
\hline MM2 & 0,4744 & 0,4113 & 0,4698 & 0,4593 & 0,3664 & 0,7471 & 0,5085 \\
\hline MM3 & 0,6160 & 0,6099 & 0,6957 & 0,6455 & 0,6950 & 0,8188 & 0,7378 \\
\hline
\end{tabular}

(Sumber: Olah Data Penelitian) 
Tabel 5 menunjukkan bahwa nilai loadings indikator menunjukkan nilai yang paling besar ke variabel terkait dibandingkan dengan nilai loadings ke variabel lain. Dengan demikian, seluruh indikator penelitian dinyatakan valid. Uji selanjutnya adalah uji signifikansi, yang dilakukan dengan melihat t-value pada model bootstrap dan membandingkan dengan nilai $\mathrm{z}$.

Tabel 5. Nilai z

\begin{tabular}{|l|l|l|l|l|l|l|l|}
\hline $\boldsymbol{a}$ & $\mathbf{0}$ & $\mathbf{0 , 0 0 1}$ & $\mathbf{0 , 0 0 2}$ & $\mathbf{0 , 0 0 3}$ & $\mathbf{0 , 0 0 4}$ & $\mathbf{0 , 0 0 5}$ & $\mathbf{0 , 0 0 6}$ \\
\hline $\mathbf{0 , 0 0}$ & & 3,090 & 2,878 & 2,748 & 2,652 & 2,576 & 2,512 \\
\hline $\mathbf{0 , 0 1}$ & 2,326 & 2,290 & 2,257 & 2,226 & 2,197 & 2,170 & 2,144 \\
\hline $\mathbf{0 , 0 2}$ & 2,054 & 2,034 & 2,014 & 1,995 & 1,977 & 1,960 & 1,943 \\
\hline $\mathbf{0 , 0 3}$ & 1,881 & 1,866 & 1,852 & 1,838 & 1,825 & 1,812 & 1,799 \\
\hline
\end{tabular}

Berdasarkan Tabel 6, penelitian yang menggunakan alpha 95\%, memiliki nilai $\mathrm{z}$ sebesar 1,960 .

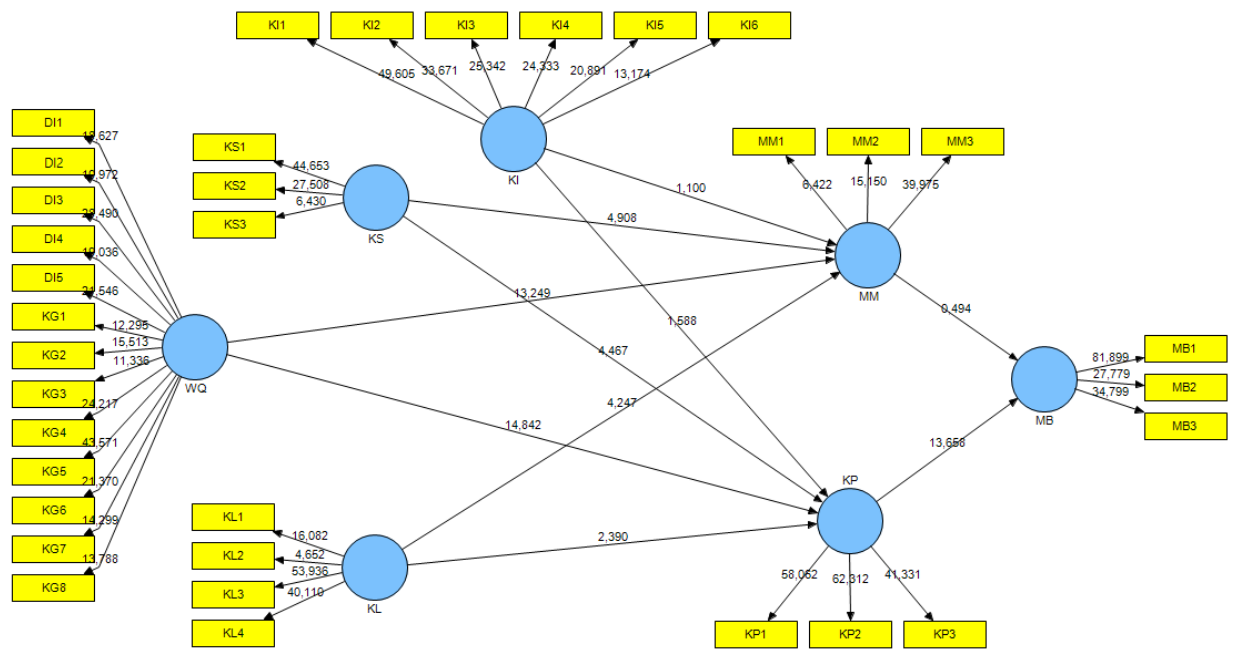

Gambar 5. Bootstrapping Output

Indikator dinyatakan signifikan apabila memiliki nilai t lebih besar dari t-tabel, yaitu 1,96. Berdasarkan Gambar 5, seluruh nilai t lebih besar dari 1,96. Dengan demikian, dapat disimpulkan bahwa seluruh indikator dalam penelitian ini signifikan. Inner models yang signifikan dapat digunakan untuk menghitung $\mathrm{Q}^{2}$ Predictive Relevance, yaitu model stuktural dalam mengukur seberapa baik nilai observasi dihasilkan oleh model. Rumus $\mathrm{Q}^{2}$ dapat dilihat dari persamaan 4 .

Berdasarkan perhitungan, didapatkan nilai $\mathrm{Q}^{2}$ sebesar $90 \%$. Analisa pengaruh dan jalur dilihat dari nilai $\mathrm{R}^{2}$ yang menunjukkan seberapa besar pengaruh indikator dalam model. Berdasarkan perhitungan $\mathrm{R}^{2}$, didapatkan nilai sebesar $84 \%$, yang berarti indikator dalam model memiliki pengaruh sebesar $84 \%$ dan sisanya sebesar $16 \%$ dipengaruhi oleh faktor lain di luar model.

\section{KESIMPULAN DAN SARAN}

\subsection{Kesimpulan}

Berdasarkan penelitian yang telah dilakukan, dapat disimpulkan bahwa indikator penelitian dan model kombinasi mendapatkan hasil signifikan terkait denga nmanfaat bersih pengguna Sistem Informasi Akademik STMIK Sunar Nusantara.. Indikator penelitian berpengaruh signifikan Model kombinasi D\&M IS Success Model dan WebQual 4.0 memiliki nilai signifikansi sebesar $90 \%$ dan $\mathrm{R}^{2}$ sebesar $84 \%$. Dengan demikian, model kombinasi ini sudah mampu menggambarkan hubungan antar indikator dengan baik. 


\subsection{Saran}

Saran yang dapat dipertimbangkan untuk penelitian selanjutnya adalah penambahan variabel eksternal lain. Misalnya, yang berkaitan dengan karakteristik responden, seperti jenis kelamin. Hal ini untuk melihat hubungan pengaruh karakteristik dalam diri responden dengan variabel pada model kombinasi D\&M IS Success Model dan WebQual 4.0.

\section{DAFTAR PUSTAKA}

Absharina, E. D., Wijaya, F. K., \& Jaya, I. D. (2018). Analisis Kesuksesan Sistem Informasi E-KKN LP2M UIN Raden Fatah Palembang dengan Menggunakan Model Delone dan Mclean. Jurnal Intelektualita: Keislaman, Sosial, Dan Sains, 7(2), 217228.

Al Fatta, H. (2007). Analisis dan Perancangan Sistem Informasi untuk keunggulan bersaing perusahaan dan organisasi modern. Andi.

Alzahrani, A. I., Mahmud, I., Ramayah, T., \& Alfarraj, O. (2017). Modelling Digital Library Success Using the Delone and Mclean Information System Success Model. Journal of Librarianship and Information Science, 1-16. https://doi.org/10.1177/0961000617726123

Aswati, S., Mulyani, N., Siagian, Y., \& Syah, A. Z. (2015). Peranan Sistem Informasi Dalam Perguruan Tinggi. Jurnal Teknologi Dan Sistem Informasi, 1(2), 79-86. Retrieved from http://is.its.ac.id/pubs/oajis/index.php/file/download_file/1466

Dalimunthe, N., \& Pertiwi, L. (2018). Analisa Kesuksesan Penerapan SIKAD UIR Dengan Model Delone dan McLean. In Konferensi Nasional Sistem Informasi (pp. 350-356). Pangkalpinang: STMIK Atma Luhur.

FKM-UNSRAT. (n.d.). Konsep Dasar dan Penerapan Sistem Informasi Kesehatan. Manado.

Ngafifi, M. (2014). Kemajuan Teknologi Dan Pola Hidup Manusia Dalam Perspektif Sosial Budaya. Jurnal Pembangunan Pendidikan: Fondasi Dan Aplikasi, 2(1), 33-47. https://doi.org/10.21831/jppfa.v2i1.2616

Rahayu, F. S., Aprilianto, R., \& Putro, Y. S. P. W. (2018). Analisis Kesuksesan Sistem Informasi Kemahasiswaan (SIKMA) dengan Pendekatan Model DeLone dan McLean. Indonesian Journal of Information Systems (IJIS), 1(1), 34-46.

Sekaran, U., \& Bougie, R. (2013). Research Methods For Business : A Skill-Building Approach. Wiley.

Tarwoto, \& Kuncoro, A. P. (2019). Evaluasi Penerapan Sistem Informasi Smart Prodi dengan Pendekatan Delone Mclean dan Framework COBIT 5 (Studi Kasus: Sistem Penjadwalan Perkuliahan STMIK Amikom Purwokerto). Jurnal MATRIK, 18(2), 222-246.

Yanti, S., \& Nugroho, H. (2018). Analisis Faktor-Faktor Penerimaan dan Niat Keberlanjutan Penggunaan Portal Akademik Siakad STMIK Akakom Menggunakan TAM Serta Model Delone dan Mclean. Jurnal Informatika Dan Komputer (JIKO), 3(1), 37-45. 